\section{PRIZE AWARDS OF THE PARIS ACADEMY OF SCIENCES.}

$A T$ the annual meeting of the Academy of Sciences, held on December 16 , I90I, the presidential address was given by M. Fouqué and the following prize awards were announced :Geometry.-M. Léonce Laugel is awarded the Francœur prize and M. Emile Borel the Poncelet prize.

Mechanics. - The extraordinary prize of six thousand francs is divided between $M$, Tissot for his work relating to the utilisation of wireless telegraphy in the Navy, and M. Marbec for his calculations on the strength of tubular boilers; $M$. Aimé Witz receives the Montyon prize, and M. Boulvin the Plumey prize for his applications of the entropy diagram to the steam engine. The Fourneyron prize, the subject proposed for which was the theoretical or experimental study of steam turbines, is not awarded.

Astronomy. - The Lalande prize to M. Thome, and the Valz prize to M. Charles André for his treatise on stellar astronomy. Physics. - The La Caze prize is awarded to M. Curie for his work on radium and on piezo-electricity of crystals, the Gaston Planté prize to M. G. Boucherot, the Kastner-Boursalt prize to MM. H. Gall and de Montlaur for their electrochemical work.

Statistics. - The Montyon prize for statistics is given to M. G. Baudran for his work on tuberculosis in the Department of the Oise, a very honourable mention being accorded to the memoir of MM. Delobel, Lebrun and Cozette on the statistics of contagious diseases of animals in France, and to M. Lowenthal.

Chemistry.-The Jecker prize is divided between MM. Moureu, Simon and Léo Vignon, MM. Wyrouboff and Verneuil receiving the $\mathrm{La}$ Caze prize for their researches on the rare metals.

Mineralogy and Geology.-The Delesse prize is awarded to M. Gaston Vasseur for his work on the classification of the Tertiary strata in the west and south-west of France.

Physical Geography. - The Gay prize is divided between MM. Franchet and Saint-Yyes.

Botany.-MM. Matruchot and Molliard receive the Bordin prize for their work on the influence of the external conditions on the protoplasm and nucleus in plants, M. Karl E. Hirn the Desmazières prize, $M$. Mazé the Montagne prize for his researches on the mechanism of the fixation of nitrogen by the Leguminosæ, M. Ferdinand Debray the de la Fons-Mélicocq prize, and M. N. Patouillard the Thore prize for his taxonomic essay on the families and genera of the Hymenomycetes.

Anatomy and Zoology. - The grand prize of the Physical Sciences is awarded to M. Maupas for his two memoirs on the biology and the origin of the sexual elements in Nematods, and the Savigny prize to MM. Jules Bonnier and Ch. Pérez for their exploration of the Red Sea and the Persian Gulf

Medicine and Surgery. - The Montyon prize is divided between MM. Buffard and Schneider, Lignières, and Claude and Baithazard, the Barbier prize between MM. Moreigne, Tissier, and Goyon, the Breant prize in equal parts between MM. Jules Courmont and V. Montagard, Weil, and Levaditi ; M. René le Fur receives the Godard prize, $\mathbf{M}$. Gley the Mége prize, whilst the Bellion prize is divided between MM. Landouzy and $\mathrm{G}$. Brouardel, and M. Sauton, very honourable mentions being accorded to M. Razou and M. Pégurier. The Lallemand prize is divided between MM. Catois, J. C. Roux and J. Lépine, MM. F. Bernheim and A. Comte receiving very honourable mention. M. Catrin receives the Baron Larrey prize for his work on mental alienation in the Army, an honourable mention being accorded to MM. Tostivint and Remlinger for their memoir on the comparative pathology of the European and Arabian races.

Physiology. - The Montyon prize for experimental physiology is awarded to M. Marcel Mirande, M. Bonniot being accorded an honourable mention, the Pourat prize to $M$. Tissot for his researches on the cooling due to muscular contraction, the $\mathrm{La}$ Caze prize to $M$. Charpentier, the Philipeaux prize being divided between MM. L. Camus and M. Moussu.

General Prizes. - The Lavoisier medal is awarded to M. Emil Fischer, professor of chemistry at the University of Berlin, correspondant of the Academy, for the whole of his works and in particular for those relating to the syntheses of the sugars. The Montyon prize (unhealthy trades) is divided between MM. Albert Dormoy and L. Vaillard, M. Halphen receiving an encouragement. M. Baubigny receives the Wilde prize for his work on atomic weights, MM. Fosse and Grignard the NO. 1679, VOL, 65]
Cahours prize (in equal parts), P. Stanislas Chevalier the Tchihatchef prize for meteorological and astronomical studies in China, M. Gabriel Lippmann the Jean Reynaud prize, M. F. Foureau the Leconte prize for his scientific explorations in southern Algeria, M. Foureau the Janssen gold medal, and MM. N. Villatte, E. Verlet-Hanus and A. P. de Chambrun silver oilt medals for their work in the Sahara, M. Gabriel Kœnigs the Petit D'Ormoy prize for his researches in geometry and mechanics, M. Bouvier the Petit D'Ormoy prize (natural sciences), M. Guichard the Saintour prize, M. A. Ponsot the Gegner prize, M. Frémont the Trémont prize.

The Baron de Joest prize is divided between MM. Verschaffel and Saint-Blancat for their astronomical work, the prize founded by Mme. la Marquise de Laplace being given to M. Japiot, and that founded by M. Félix Rivot to M.M. Pellarin, Ott, Japiot and Guillaume.

\section{ELECTRIC WAVES.}

THE annual meeting of the German Association of Men of Science and Physicians was held last autumn in Hamburg. It is twenty-five years since the Association last met in the birthplace of Heinrich Hertz, who was then a young man of nineteen, not yet entered upon the active period of his life, which ended by his death in 1894 , and which, though so short, was yet so great and full of usefulness. It fell, therefore, to the lot of Prof. Ernst Lecher to deliver this address ${ }^{1}$ in memory of Hertz and to review the further development, which has taken place since his death, of his greatest work, the experimental proof of the existence of electric waves.

It is, indeed, a long chain of events, as Hertz himself expressed it, to which the discovery of electric waves belongs, one event linking itself into another, the whole forming perhaps the most noble and convincing proof that our modern methods of scientific thought and research are true and exact. Prof. Lecher gives an interesting sketch of this in the pamphlet before us. The first link in the chain was forged by Faraday. Unti his time the scientific world was dominated by the old Newtonian ideas of force acting at a distance, an idea which seems to us now, on close examination, to be manifestly absurd. It required, however, the genius of Faraday to breai loose from this line of thought and to perceive that a medium is necessary in order that one body may exert a force upon another ; and to the eye of Faraday the whole of space became filled with lines and tubes of force, real changes of condition in the intervening media, which, although invisible, were as clear to him as the objects acted upon themselves. The way was thus paved for Maxwell, who collected these ideas in his really magic formula of the electrodynamical theory of light. According to Maxwell there are electric currents in insulators, these being of the nature of displacement currents. Although these currents are of very short duration, yet they must have like magnetic and inductive effects to the ordinary currents in a conductor. If, now, a displacement current vibrates backwards and forwards, then in a neighbouring insulator displacement currents will be induced and so forth ; a transversal wave-motion is thus propagated until it is absorbed by induction in a conductor and transformed into heat. On calculating the velocity of this wave propagation it was found that two quantities appeared in the result-the dielectric coefficient and the permeability. The square of the velocity is equal to the reciprocal value of the product of these two values. It was found, however, that whole powers of this value were always appearing in different branches of the theory of electricity, and, most extraordinarily to say, the value was always found to be equal to the velocity of light. Maxwell, therefore, came to the theoretical conclusion in 1865 that an electromagnetic wave must travel in an insulator, e.g. in air or vacuum, with the velocity of light. But not only the velocity, concluded Maxwell, should be the same, but also the geometrical and other properties must be equal; a ray of light was therefore a series of electric waves, light was electricity. These ideas, immediately after their enunciation by Maxwell, did not meet with any great acceptance, and an experimental proof of their accuracy was looked upon as being altogether out of the question. This feeling was even shared by Hertz himself, for in his description of his classical experiment where, by means of a

Ueber die Entdeckung der elektrischen Wellen durch $\mathrm{H}$. Hertz und die weitere Entwicklung dieses Gebietes. (Leipzig : Johann Ambrosius Barth. 